\title{
Correlation of the academic and clinical performance of Libyan nursing students
}

\author{
Dorothy G. Buhat-Mendoza, J ames Neil B. Mendoza, Cristina T. Tianela, Eduardo L. Fabella \\ College of Nursing, Omar Al-Mukhtar University, Tobruq, Libya
}

Correspondence: James Neil B. Mendoza. Address: College of Nursing Omar Al-Mukhtar University College of Nursing, Tobruq, Libya. Email: jameshack45@hotmail.com or jameshack45@gmail.com

Received: J une 24, 2014

DOI : 10.5430/jnep.v4n11p82
Accepted: August 21, 2014

URL: http://dx.doi.org/10.5430/jnep.v4n11p82

\section{Abstract}

Background: Theoretical knowledge acquired in the classroom setting is necessary to enhance the clinical performance of nursing students in the same way that the latter reinforces what is learned in the classroom. However academic grade does not always reflect the competence of students in clinical setting. This study was conducted to determine a possible correlation between student academic performance in the nursing specialization subjects and their clinical performance.

Design and Method: The research employed a descriptive non-experimental approach using existing data sets. The grades of three batches of Omar Al-Mukhtar University College of Nursing (Libya) students were retrieved from the Office of the College Registrar and subjected to statistical analysis. Pearson Product Moment Coefficient was utilized to determine the relationship in the changes and movement of the two variables, Academic and Clinical Performance.

Result: Positive correlation between academic and clinical performance was observed from the three groups of students considered in this study. Correlation was noted to consistently increase from the third to the fourth year for the two most recent batches of students suggesting enhanced appreciation of theoretical and clinical nursing among students. Students who perform well in the classroom setting performed similarly well in the clinical setting.

Conclusion: The Academic Performance of 3rd and 4th year BS Nursing students of Omar Al-Mukhtar University College of Nursing correlates well with their Clinical Performance. This indicates that an academic performer rates as well in their clinical focus and may be attributed to their increased appreciation of nursing as they reach a higher year level.

\section{Key words}

Academic performance, Nursing specialization, Clinical performance, Nursing students, Nursing education

\section{I ntroduction}

The world of nursing and healthcare is rapidly changing. The impact of these changes together with an acute nursing shortage puts pressure on nursing education programs to teach a larger number of students a greater amount of information in an efficient manner ${ }^{[1]}$. The World Health Organization reported in November 2013 a global shortage of medical workers including nurses at around 7.2 million and it was expected to rise to 12.9 million in $2035^{[2]}$. With the expected nursing shortage comes hospitals' increased hiring of new graduates with minimal orientation time ${ }^{[3]}$. Unfortunately, new graduates often prove to lack competence to perform in the real nursing environment ${ }^{[4]}$, in addition to the role conflict and stress they experience as they begin practice in work environment ${ }^{[5]}$. 
The education of nurses had traditionally been conducted in the hospital-based setting. Over the last few decades however, many countries offered nursing education as a tertiary level-based course. Reasons for this move were numerous with the main goal being to improve the educational experience of students and thus the competence of graduates ${ }^{[6]}$. Although there is widespread agreement exists that clinical experience is central to learn nursing, a finding suggests that teachers' and students' focus on task completion rather than a deeper understanding and readiness for nursing practice ${ }^{[7]}$. The idealistic rule bound classroom setting and intuition based clinical setting differs that dissonance might occur if not properly guided by clinical instructors, thus resulting in disillusionment and devaluation in nursing performance ${ }^{[8]}$. Students also have the notion of nursing theory and practice as a divided discipline. In an article by Greenwood, it was explained that undergraduate nurses perceive that nursing theory is only learned from nursing academics and literature while clinical skills can only be learned through experience in the field with clinical nurses ${ }^{[9,10]}$. These misconceptions pose a possible problem as academic performance of students might not reflect in their clinical competence.

As a result of the shift of nursing education to the tertiary sector, the main educators of nursing students (i.e. academics) are no longer based in hospitals. This creates a barrier to academics continuing contact with the clinical environment and maintaining clinical credibility or competence. The faculty in charge with theoretical knowledge and clinical practice are equipped to deliver education to students as they apply theory to practice, the question is if they will provide enough support as a mentor to students ${ }^{[11]}$. Although teaching role can be done with the help of staff nurse during clinical practice, workload and lack of formal preparation as mentor hinders them to perform such functions ${ }^{\text {[12] }}$.

Nursing theory is relative to clinical practice, as nursing education involves both theoretical and practical process ${ }^{\text {[13] }}$. Theory helps to improve nursing practice by providing the proper knowledge needed to increase nursing's power and professional autonomy guiding practice, education and research ${ }^{[9,14]}$. In nursing education, clinical learning plays an important role in enriching clinical competences of nursing students as it provides an anticipatory knowledge of the organizational contexts in which nursing care is delivered ${ }^{[15]}$. According to Ironside among others, clinical education is a time- and resource-intensive aspect of contemporary nursing programs ${ }^{[7]}$. A study imploring clinical role in partnership with academic role will help the research/practice gap and assist in facilitating evidence-based clinical practice ${ }^{[16]}$. Iranian authors concluded that the clinical area is the venue where students must relate theory to practice, learn the necessary technical and interpersonal skills, make clinical judgments, become socialized into the profession, and begin to appreciate its values and ethics ${ }^{[13]}$.

A review of the clinical role of nurse lecturer in considering competence must be addressed as well for the closure of theory-practice gap as discussed by Barrett that the actual transfer of knowledge to clinical situation occurs in practice ${ }^{[17]}$.

The nursing curriculum of Omar Al-Mukhtar University College of Nursing (OMU CON) combines theoretical and practical instruction. The basic sciences and nursing subjects are mostly completed in the first two years of education. Upon entering their third year, however, nursing students choose from four areas of specialization: Operating Theater and Anesthesia Nursing, Intensive and Emergency Nursing, Maternal and Neonatal Nursing and Public Health Nursing. Their choice determines the Nursing Specialization subjects and clinical exposure areas. Students are required to complete a competency-based intensive nursing practicum (INP) during the $3^{\text {rd }}$ and $4^{\text {th }}$ years of nursing education. This hospital or clinic-based exposure serves as the practicum component of the nursing course.

Students who elect to specialize in Operating Theater and Anesthesia Nursing (OTAN) are trained to provide specialized care to patients who undergo surgical treatment. Those who choose Intensive and Emergency Nursing (IEN) specialization are trained to provide health care services to acutely and chronically-ill clients in hospital settings and in long term care facilities and in the community. OMU CON students who specialize in Maternal and Neonatal Nursing (MNN) are instructed on the special needs of women and Pediatric patients and are trained to provide care to mothers during pregnancy, delivery and during the post-partum period. Finally, students who choose to specialize in Public Health Nursing are trained for the practice of professional nursing in a variety of public health nursing care settings. Choosing the 
correct specialization is crucial to students' clinical performance. In a study about clinical placement, it was shown that nursing students' satisfaction with the placement does not differ between clinical settings as meaningful and multi dimensional learning situation occurs but some clinical setting still poses learning objective difficult to achieve ${ }^{\text {[18] }}$.

This research was conducted to determine if correlation exists between the academic and clinical performance of 3rd and 4th year nursing students of Omar Al-Mukhtar University. Determining the level of academic performance and level of clinical performance of students together with their significant association may be used to predict nursing success. Furthermore, the researchers want to validate whether the students' appreciation of theory is reflected in their clinical performance.

\section{Methods}

The research employed a descriptive non-experimental approach using existing data sets. The grades in the academic subjects and clinical rotation of three batches of Omar Al-Mukhtar University College of Nursing students were retrieved from the Office of the College Registrar and subjected to statistical analysis. Pearson Product Moment Coefficient was utilized to determine the relationship in the changes and movement of the two variables, Academic and Clinical Performance.

\subsection{Students grades}

The official students' grades of $3^{\text {rd }}$ year and $4^{\text {th }}$ year students of Academic Year (AY) 2009-2010, 2010-2011 and 2011-2012 were retrieved from the records of the Registrar of the College of Nursing. For the purposes of this research, the term Academic Performance was used to represent grades obtained by 3rd year students in Nursing Specialization (NS) 1 and 2 and by 4th year students in Nursing Specialization 3 and 4. Clinical performance refers to the grades obtained by 3rd year students in Intensive Nursing Practicum (INP) 1 and 2 and by 4th year students in Intensive Nursing Practicum 3 and 4. To facilitate statistical analysis, students who officially dropped out from the class in either Academic or Clinical subjects were removed from the analysis.

\subsection{Study population}

The study population consisted of three batches of students. Batch 2008, the pioneer batch, entered the College of Nursing on AY 2007-2008. Academic and Clinical performances from this batch were obtained from AY 2009-2010 ( $3^{\text {rd }}$ year) and AY 2010-2011 ( $4^{\text {th }}$ year). Batch 2009 consists of students who entered the College of Nursing in 2008-2009. For this current study, this batch also includes returning students from Batch 2008. Academic and Clinical performances for batch 2009 were obtained from AY 2010-2011 ( $3^{\text {rd }}$ year) and AY 2011-2012 ( $4^{\text {th }}$ year). The third batch of students in this study is Batch 2010. This consists of students who began their nursing education in AY 2009 -2010. The statistical analysis for this batch also included returning students from Batch 2008 and Batch 2009. Academic and Clinical performances for batch 2010 were obtained from AY 2011-2012 (3 $3^{\text {rd }}$ year) and AY 2012-2013 ( $4^{\text {th }}$ year).

\subsection{Data collection}

The study period lasted for four months (March to June 2014). Data was collected from the Registrar's Office and manually recorded before being subjected to data measures. Reliability testing was not performed since data were official university records.

\subsection{Data measures}

Collected data were tallied and organized into tables to permit ease of analysis. Three measures of central tendency (mean, median and mode) were computed individually for the academic and clinical grades. Pearson Product Moment Coefficient was utilized to determine the relationship in the changes and movement of the two variables, Academic and Clinical Performance. Software application Microsoft Excel 2007 was used to tally, perform statistical measurements, and generate tables and figures of the collected data. 


\section{Results}

\subsection{Academic performance of nursing students}

Batch 2008 recorded the highest $3^{\text {rd }}$ year and $4^{\text {th }}$ year academic performance mean of 73.04 and 74.65 , respectively. On the other hand Batch 2010 had a mean score of 64.22 for $3^{\text {rd }}$ year and 60.97 for $4^{\text {th }}$ year level, the lowest among three batches (see Table 1).

Table 1. Academic Performance of Nursing Students in Nursing Specialization Subjects

\begin{tabular}{llllll}
\hline Batch & Level & N & Mean & Median & Mode \\
\hline \multirow{2}{*}{ Batch 2008} & $3^{\text {rd }}$ & 126 & 73.04 & 74.00 & 60 \\
\multirow{2}{*}{ Batch 2009} & $4^{\text {th }}$ & 93 & 74.65 & 73.50 & 69 \\
\multirow{3}{*}{ Batch 2010} & $3^{\text {rd }}$ & 69 & 73.01 & 75.00 & 66 \\
& $4^{\text {th }}$ & 101 & 64.14 & 67.00 & 65 \\
(1d & 90 & 64.22 & 63.75 & 65 \\
\hline
\end{tabular}

\subsection{Clinical performance of nursing student}

Clinical Performance mean of Batch 2009 for $3^{\text {rd }}$ year of 74.27 is the highest among the group as seen in Table 2 while Batch 2008 recorded the highest $4^{\text {th }}$ year mean score of 77.92 . The lowest $3^{\text {rd }}$ year mean score of 67.74 belonged to Batch 2010 as well as the lowest in the $4^{\text {th }}$ year category with 60.97 (see Table 2).

Table 2. Clinical Performance of Nursing Students in Intensive Nursing Practicum

\begin{tabular}{llllll}
\hline Batch & Level & N & Mean & Median & Mode \\
\hline \multirow{2}{*}{ Batch 2008 } & $3^{\text {rd }}$ & 126 & 72.23 & 73.50 & 68 \\
\multirow{3}{*}{ Batch 2009 } & $4^{\text {th }}$ & 93 & 77.92 & 80.00 & 81 \\
\multirow{3}{*}{ Batch 2010 } & $3^{\text {rd }}$ & 69 & 74.27 & 76.50 & 81 \\
& $4^{\text {th }}$ & 101 & 66.17 & 68.50 & 65 \\
\hline
\end{tabular}

\subsection{Relationship between academic and clinical performance of BSN students}

Positive correlation between Academic Performance and Clinical Performance was noted for both year levels across the three groups of students considered in this study ranging from substantial level to very high level of correlation. The highest correlation $(r=0.8777)$ interpreted as a very high relationship was observed on the $4^{\text {th }}$ year of Batch 2009. Correlation was lowest $(r=0.5678)$ for the $4^{\text {th }}$ year of Batch 2008. However, the association between these variables was still substantial (see Table 3).

Table 3. Correlation Between Academic and Clinical Performance of BSN Students

\begin{tabular}{llll}
\hline Batch & Level & $\boldsymbol{r}$ & Interpretation \\
\hline \multirow{2}{*}{2008} & $3^{\text {rd }}$ & 0.7690 & High \\
& $4^{\text {th }}$ & 0.5678 & Substantial \\
2009 & $3^{\text {rd }}$ & 0.6286 & Substantial \\
& $4^{\text {th }}$ & 0.8777 & Very High \\
& $3^{\text {rd }}$ & 0.6903 & Substantial \\
\hline
\end{tabular}

Note. $r$ from .00 to +-.20 indifferent, or negligible relationship (I); $r$ from .21 to +-.40 low correlation or slight relationship (L); $r$ from .41 to +-.70 substantial or marked relationship (S); $r$ from .71 to +-.99 high to very high relationship (H); $r$ from +-1.00 perfect relationship (P). 


\subsubsection{Relationship between academic and clinical performance of batch 2008}

Batch 2008's Academic Performance correlated well and positively (see Figure 1\&2) with Clinical Performance during their $3^{\text {rd }}(r=0.7690)$ and $4^{\text {th }}$ year levels $(r=0.5678)$ with a corresponding interpretation of High and Substantial correlation, respectively (see Table 4). Although the mean grades increased from $3^{\text {rd }}$ to $4^{\text {th }}$ for both INP and NS, there was a higher correlation for $3^{\text {rd }}$ year level than the $4^{\text {th }}$.

Table 4. Correlation Between Academic and Clinical Performance Batch 2008 BSN Students

\begin{tabular}{lllllll}
\hline Level & Subject & N & Mean & SD & $\boldsymbol{r}$ & Interpretation \\
\hline \multirow{2}{*}{$3^{\text {rd }}$} & INP & 126 & 72.23 & 13.47 & \multirow{2}{*}{ High } \\
& NS & 126 & 73.04 & 15.03 & & \\
$4^{\text {th }}$ & INP & 93 & 77.92 & 10.05 & \multirow{2}{*}{ Substantial } \\
\hline
\end{tabular}

Note. INP = Intensive Nursing Practicum; NS = Nursing Specialization

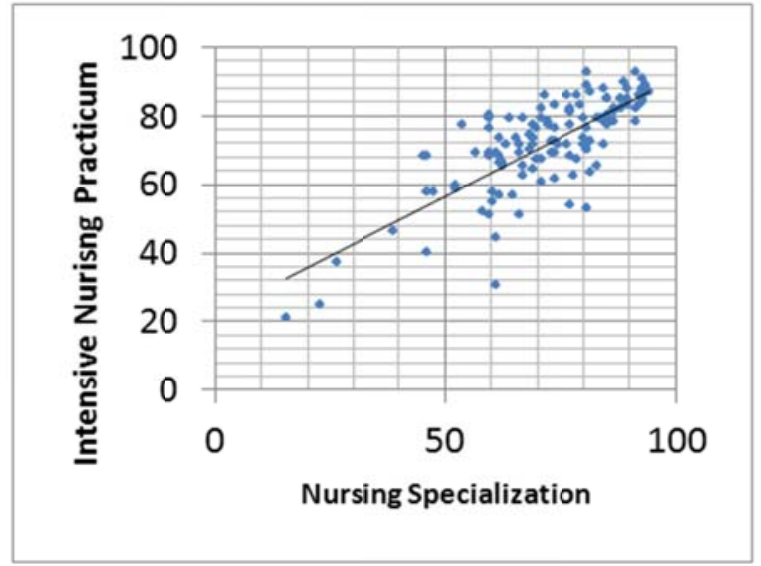

Figure 1. Correlation Between $3^{\text {rd }}$ Year Academic and Clinical Performance, Batch 2008

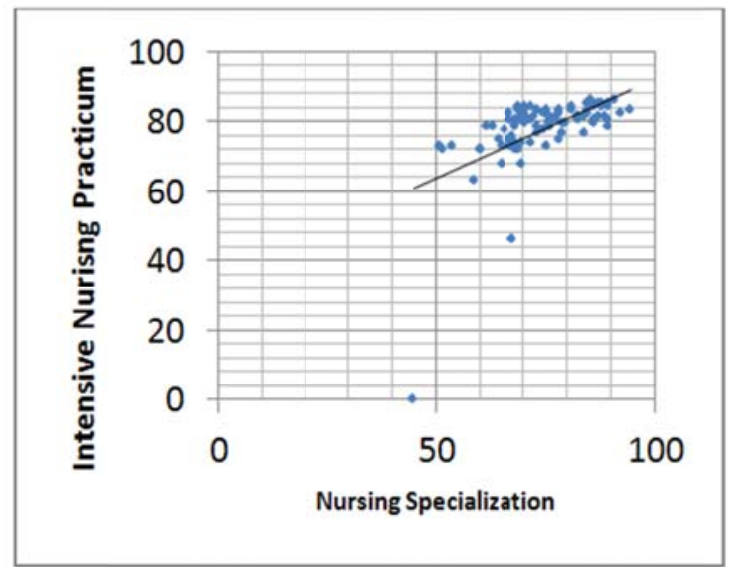

Figure 2. Correlation Between $4^{\text {th }}$ Year Academic and Clinical Performance, Batch 2008

\subsubsection{Relationship between academic and clinical performance of batch 2009}

The Academic Performance and Clinical Performance of Batch 2009 associated well with a $3^{\text {rd }}$ year $r$ of 0.6286 interpreted as substantial positive correlation (see Table 4, Figure 3) and $4^{\text {th }}$ year $r$ of 0.8777 or a very high positive correlation (see Table 5, Figure 4). Increase of students from 69 to 101 and a high dispersion of 16.97 for INP and 16.22 for NS were apparent even if there was a drop on mean score from $3^{\text {rd }}$ to $4^{\text {th }}$ year level.

Table 5. Correlation Between Academic and Clinical Performance Batch 2009 BSN Students

\begin{tabular}{lllllll}
\hline Level & Subject & n & Mean & SD & r & Interpretation \\
\hline \multirow{2}{*}{ 3rd } & INP & 69 & 74.27 & 13.47 & \multirow{2}{*}{ Substantial } \\
& NS & 69 & 73.01 & 15.29 & & \\
\multirow{2}{*}{ 4th } & INP & 101 & 66.17 & 16.97 & & Very High \\
& NS & 101 & 64.14 & 16.22 & 0.8777 & \\
\hline
\end{tabular}

Note. INP = Intensive Nursing Practicum; NS = Nursing Specialization

\subsubsection{Relationship between academic and clinical performance of batch 2010}

Although Batch 2010 scores the lowest grades mean compared to either Batch 2008 or Batch 2009, their Clinical Performance still correlated well with their Academic Performance with a $3^{\text {rd }}$ year $r$ of 0.6903 and $4^{\text {th }}$ year $r$ of 0.7344 , 
having a substantial correlation and high correlation interpretation, respectively (see Table 6) and a positive correlation at that (see Figure 5\&6). The batch has the lowest difference (increase/decrease) in mean score and frequency thus lesser $r$ interval, even with a big increase in their deviation from $3^{\text {rd }}$ Level INP of 10.21 and NS of 11.85 to $4^{\text {th }}$ Level INP of 17.38 and NS of 14.76 .

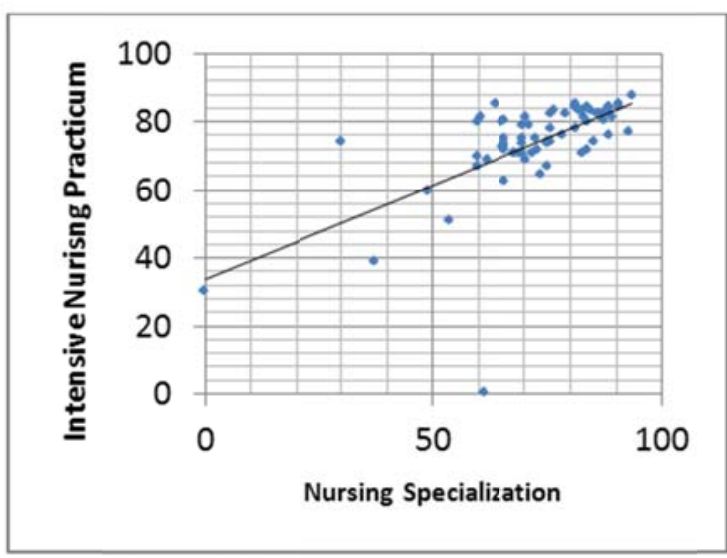

Figure 3. Correlation Between $3^{\text {rd }}$ Year Academic and Clinical Performance, Batch 2009

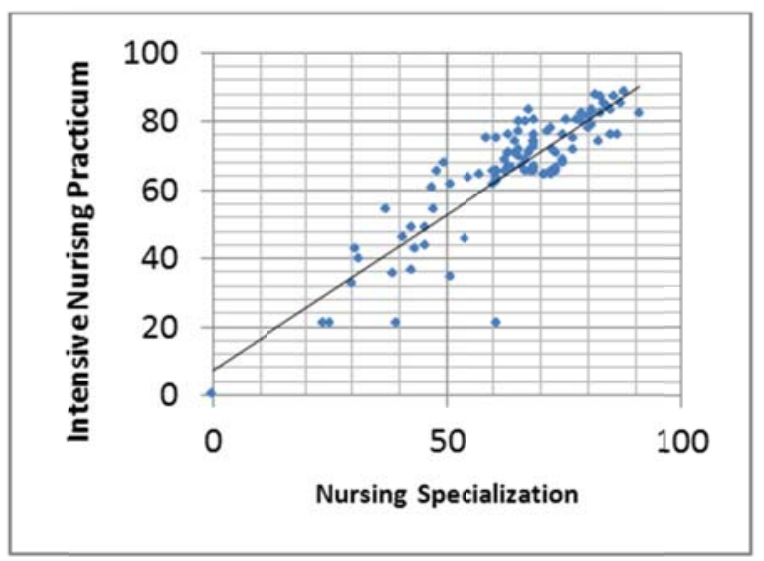

Figure 4. Correlation Between $4^{\text {th }}$ Year Academic and Clinical Performance, Batch 2009

Table 6. Correlation Between Academic and Clinical Performance Batch 2010 BSN Students

\begin{tabular}{lllllll}
\hline Level & Subject & $\mathbf{n}$ & Mean & SD & $\boldsymbol{r}$ & Interpretation \\
\hline \multirow{2}{*}{ 3rd } & INP & 90 & 67.74 & 10.21 & \multirow{2}{*}{ Substantial } \\
& NS & 90 & 64.22 & 11.85 & & \\
\multirow{2}{*}{4 th } & INP & 105 & 61.62 & 17.38 & \multirow{2}{*}{ High } & \\
& NS & 105 & 60.97 & 14.76 & & \\
\hline
\end{tabular}

Note. INP = Intensive Nursing Practicum; NS = Nursing Specialization

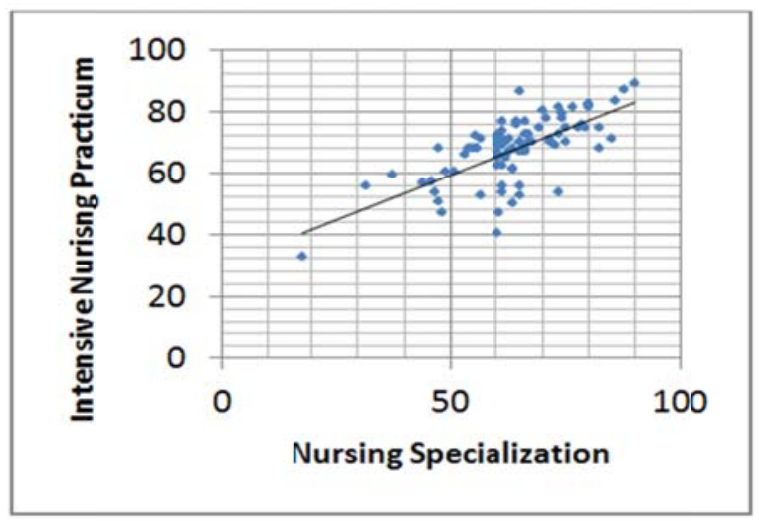

Figure 5. Correlation Between $3^{\text {rd }}$ Year Academic and Clinical Performance, Batch 2010

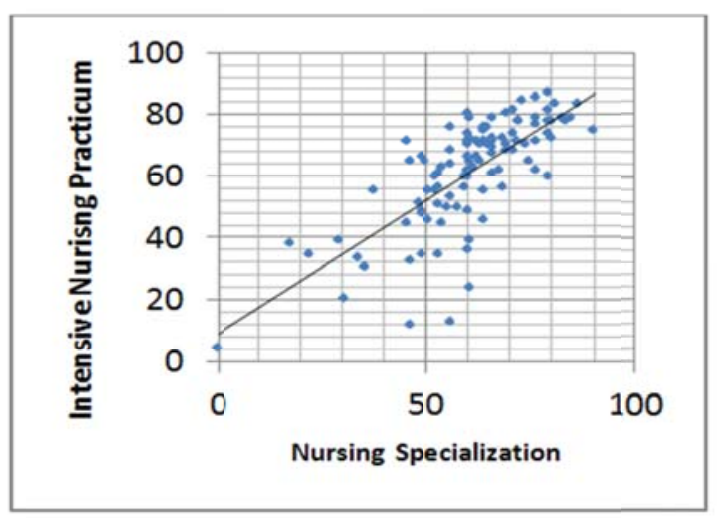

Figure 6. Correlation Between $4^{\text {th }}$ Year Academic and Clinical Performance. Batch 2010

\section{Discussion}

The research showed that the academic performance of students of Omar Al Mukhtar University College of Nursing correlated positively with their clinical performance. Yoho's study in a different medical science showed a similar correlation between academic performance with clinical performance of students ${ }^{[19]}$. It was evident that a good 
performing student in academics will most likely to perform better in clinical setting as a study by Jecklin suggests that students which possess mastery on the subject matter tend to be more elaborative on his approach ${ }^{[20]}$. Academic performers tend to practice more compared to poor performers, resulting in a higher correlation of INP and NS. Ahonen relates theory to practice by this excerpt,

"Applying classroom concepts to actual practice is an exciting and anticipated part of the curriculum for young, eager nursing students. They arrive with theory, knowledge, and simulated laboratory experience, ready to practice nursing skills on real patients." ${ }^{[12]}$

As evidenced from the result, a higher standard deviation resulted in a higher correlation interpretation of NS and INP (see Table 4-6). Higher deviation existed because good standing students performed and granted a higher mark way better than lower standing students, unlike the result of $4^{\text {th }}$ year Batch 2008 which has the lowest standard deviation causing the lowest correlation of the subjects as well (see Table 4). Institutional standardization/revision of the grading system on nursing subjects implemented from Batch $20094^{\text {th }}$ year level (AY 2011-2012) and beyond might have contributed to the result, since it causes high dispersion or deviation of results.

Low standing students with poor performance in academics also did not perform well in clinical setting. This contributed to higher correlation result as the spread tends to be more linear (see Figure 1-6). Poor performance contributed to attrition as the decrease in Batch 2008 student population (see Table 1) was partly due to the non-promotion due to failure and voluntary attrition (drop-out) of some students. Attrition contributed to the drop in correlation result of Batch $20083^{\text {rd }}$ year to $4^{\text {th }}$ year comparison (see Table 4), whereas increases in the number of students' have a tendency of increasing correlation of INP and NS as well (see Table 5\&6). The high attrition among nursing students suggested a need to enhance the selection and admission procedures of the College of Nursing. Identifying the factors into categories like what was explained by Pitt among others, that potentially impact nursing students' academic performance and attrition includes demographic, academic, cognitive, and personality/behavioral factors ${ }^{[21]}$. The biggest impediment in clinical practice would be students' lack of interest and motivation in the clinical setting ${ }^{[22]}$.

The result of the study validated the students' appreciation of theory as it was reflected in their clinical performance through high correlation interpretation. However, many students of Omar Al Mukhtar University College of Nursing are observed by clinical instructors to be more interested with marks received rather than actual learning, although this requires further validation. Nevertheless, this connotes that the respondents were using surface learning strategies especially if the workload of clinical focus were too much to bear as explained in the study of Liou among others ${ }^{[23]}$.

Despite the positive correlation result of the study the academic and clinical performance grades of students are susceptible to rater bias since different clinical instructors assess the performance of students in the different specializations and in different clinical areas. Similarly, academic performance must be validated by a standardized examination for students based on College-identified core competencies. To address rater biases, a well-designed clinical assessment tool for student's clinical performance including case study and objective clinical structure exam will be a fair and reliable method ${ }^{[24]}$. Additionally a study by Coombs et al outlines several clinical academic roles from beginners to professor level, understanding the nature and contribution these roles can make in the organization ${ }^{[25]}$. Perhaps tools like Cognitive Dissonance Theory, the Novice to Expert Model, and the Neuman Systems Model serve as a theoretical foundation for recommended strategies and interventions for optimal response to dissonance between academic ideal and clinical reality in nursing students ${ }^{[8]}$. Development of an accelerated nursing programs focusing on the challenges on both clinical and academic experiences via immersions ${ }^{[26]}$ can also be adopted. Rethinking learning in practice would be a good strategy as well as, Ironside says even if current clinical experiences is central to learning nursing little is known if it contributes to learning and readiness of students to practice. She added that understanding first what occurs in clinical practice, before studying and conducting educational interventions ${ }^{[7]}$. 
To further the high positive correlation of INP and NS, some recommendation would suffice for clinical competency. Proper clinical placement may well be suited to the students' learning outcome as attention must be paid to whether the setting offers the student a meaningful learning situation where the appropriate learning outcome may be achieved ${ }^{[18]}$. Development of a comprehensive and appropriate evaluation tool for clinical competencies to upgrade what was currently used which was somewhat traditional and sometimes limited evaluation method would be essential ${ }^{[13]}$.

Despite non appearance of low correlation in the study, the authors would like to suggest enhancement of theory to practice as well to strengthen the correlation further. Though a study in Ireland prompts that clinical practice posed a problematic component in its academic identity it should remain as the central component in nursing education ${ }^{\text {[27] }}$. McNamara furthers that there be a need to reconfigure academic nursing with clinical nursing ${ }^{\text {[27] }}$. Through it all nursing competence correlates with critical thinking and critical thinking increases with further education (academic) or longer working experience (clinical) ${ }^{[28]}$ and evolves through learning processes ${ }^{[29]}$. Evidence also suggests that educational intervention improved clinical competence of practitioners ${ }^{[30]}$ and a need for inter professional education such as nursing were being called for ${ }^{[31]}$.

\section{Conclusion}

The Academic Performance of 3rd and 4th year BS Nursing students of Omar Al-Mukhtar University College of Nursing correlates well with their Clinical Performance. This indicates that students' who perform well in academics rate as well in their clinical focus. This may be attributed to their increased appreciation of nursing as they reach a higher year level. Factors affecting student selection, admission, and attrition as well as clinical instructor factors may have to be re-evaluated to standardized and stabilized academic and clinical delivery and education thus to enhance the progress of the College as an institution and nursing as a profession.

\section{References}

[1] Sand-Jecklin K. The impact of active/cooperative instruction on beginning nursing student learning strategy preference: Nurse Education Today. 2007; 27: 474-480. PMid:17030077 http://dx.doi.org/10.1016/j.nedt.2006.08.006

[2] World Health Organization. Global health workforce shortage to reach 12.9 million in coming decades. Nov. 2013. Available from: http://www.who.int/mediacentre/news/releases/2013/health-workforce-shortage/en/

[3] Goode, C.J., Lynn, M.R., Krsek, C., Bednash, G.D. Nurse residency programs: an essential requirement for nursing. Nursing Economic. 2009; 27 (3): 142-159. PMid:19558074

[4] Liou, S., Chang, C., Tsai,H.,\& Cheng, C. The effects of a deliberate practice program on nursing students' perception of clinical competence: Nurse Education Today. 2013; 33: 358-363. PMid:22858306 http://dx.doi.org/10.1016/j.nedt.2012.07.007

[5] Fink R, Krugman M, Casey K, Goode C. The graduate nurse experience: qualitative residency program outcomes. J Nurs Adm. 2008 Jul-Aug; 38(7-8): 341-8. PMid:18690125 http://dx.doi.org/10.1097/01.NNA.0000323943.82016.48

[6] Elliott,M., \& Wall, N.. Should nurse academics engage in clinical practice? Nurse Education Today. 2008; $28: 580-587$. PMid:18055069 http://dx.doi.org/10.1016/j.nedt.2007.09.015

[7] Ironside P., McNelis A., Ebright P. Clinical education in nursing: Rethinking learning in practice settings. Elsevier Inc. 2014. http://www.sciencedirect.com/science/article/pii/S0029655413002455

[8] Meyer T, Xu Y. Academic and clinical dissonance in nursing education: are we guilty of failure to rescue? Nurse Educ. 2005; 30(2): 76-9. http://dx.doi.org/10.1097/00006223-200503000-00010

[9] Graham J. Nursing theory and clinical practice: how three nursing models can be incorporated into the care of patients with end stage kidney disease. CANNT J. 2006 Oct-Dec; 16(4):28-31. Available from: http://www.ncbi.nlm.nih.gov/pubmed/17252898 PMid:17252898

[10] Greenwood J. Nursing theory. In J. Daly, S. Speedy, \& D. Jackson, Contents of nursing: An introduction. 2000. Sydney: MaClennant Petty.

[11] Andreas I. loannides. The nurse teacher's clinical role now and in the future. Nurse Education Today. 1999; 19: 207-214. http://dx.doi.org/10.1016/S0260-6917(99)80006-9 
[12] Ahonen K., Quinlan C. Role of the staff nurse in undergraduate nursing education. American Nurse Today May. 2013; 8(5). Available from: http://www.americannursetoday.com/article.aspx?id=10306\&fid=10226

[13] Rafiee G., Moattari M., Nikbakht A., Kojuri J., Mousavinasab M. Problems and challenges of nursing students’ clinical evaluation: A qualitative study. Iran J Nurs Midwifery Res. 2014 Jan-Feb; 19(1): 41-49. Available from: http://www.ncbi.nlm.nih.gov/pmc/articles/PMC3917184/

[14] Marriner-Tomey, A. Introduction to analysis of nursing theories. In A. Marriner-Tomey (3rd ed.), Nursing theorists and their work. St. Louis 2013, MO: Mosby-Year Book

[15] Tomietto M., Rappagliosi C., Sartori R., Battistelli A. Clinical learning in nursing education as a factor to enhance organizational socialization in newcomer Nurses. Journal of Nursing Education and Practice. 2014; 4(8). Available from: http://www.sciedu.ca/journal/index.php/jnep/article/view/4300/2784 http://dx.doi.org/10.5430/jnep.v4n8p1

[16] Currey J., Considine J., Khaw D. Clinical nurse research consultant: a clinical and academic role to advance practice and the discipline of nursing. J Adv Nurs. 2011; 67(10): 2275-83. PMid:21592190 http://dx.doi.org/10.1111/j.1365-2648.2011.05687.x

[17] Barrett D.The clinical role of nurse lecturers: Past, present,and future : Nurse Education Today. 2013; 27: $367-374$. PMid:16914233 http://dx.doi.org/10.1016/j.nedt.2006.05.018

[18] Bisholt B., Ohlsson U., Engström A., Johansson A., Gustafsson M. Nursing students' assessment of the learning environment in different clinical settings. Nurse Education in Practice. published online 18 December 2013. Available from: http://www.nurseeducationinpractice.com/article/S1471-5953(13)00209-6/abstract

[19] Niederhauser V., Schoessler M., Gubrud-Howe P., Magnussen L., Codier E. Creating Innovative Models of Clinical Nursing Education. Journal of Nursing Education. 2012; 51(10). Available from: http://www.njni.org/sites/default/files/Innovative\%20Clinical\%20Models.pdf PMid:23061436

[20] Sand-Jecklin K. The impact of active/cooperative instruction on beginning nursing student learning strategy preference: Nurse Education Today. 2007; 27: 474-480. PMid:17030077 http://dx.doi.org/10.1016/j.nedt.2006.08.006

[21] Pitt V; Powis D; Levett-Jones T. Factors influencing nursing students' academic and clinical performance and attrition: an integrative literature review. Nurse Educ Today. 2012; 32(8):903-13. Available from: http://reference.medscape.com/medline/abstract/22595612 PMid:22595612 http://dx.doi.org/10.1016/j.nedt.2012.04.011

[22] Rahimi A., Ahmadi F. The obstacles and improving strategies of clinical education from the viewpoints of clinical instructors in Tehran’s Nursing Schools. Iranian Journal of Medical Education. 2005; 5(2): 73-80.

[23] Liou, S., Chang, C., Tsai,H.,\& Cheng, C., The effects of a deliberate practice program on nursing students' perception of clinical competence: Nurse Education Today. 2013; 33: 358-363. PMid:22858306 http://dx.doi.org/10.1016/j.nedt.2012.07.007

[24] Boursicot KA. Structured assessments of clinical competence. Br J Hosp Med (Lond). 2010; 71(6): 342-4. Available from: http://reference.medscape.com/medline/abstract/20551875 http://dx.doi.org/10.12968/hmed.2010.71.6.48450

[25] Coombs M, Latter S, Richardson A. Developing a clinical academic career pathway for nursing. Br J Nurs. 2012; 21(18):1084-6, 1088-90. PMid:23123839 http://dx.doi.org/10.12968/bjon.2012.21.18.1084

[26] Caldwell LM, Tenofsky LM, Nugent E. Academic and clinical immersion in an accelerated nursing program to foster learning in the adult student. Nurs Educ Perspect. 2010 Sep-Oct; 31(5): 294-7. Available from: http://www.ncbi.nlm.nih.gov/pubmed/21086867 PMid:21086867

[27] McNamara MS. Where is nursing in academic nursing? Disciplinary discourses, identities and clinical practice: a critical perspective from Ireland. J Clin Nurs. 2010; 19(5-6): 766-74. PMid:20500320 http://dx.doi.org/10.1111/j.1365-2702.2009.03079.x

[28] Chang MJ, Chang YJ, Kuo SH, Yang YH, Chou FH. Relationships between critical thinking ability and nursing competence in clinical nurses. J Clin Nurs. 2011; 20(21-22): 3224-32. Available from: http://reference.medscape.com/medline/abstract/21414054 PMid:21414054 http://dx.doi.org/10.1111/j.1365-2702.2010.03593.x

[29] Andreou,C., Papastavrou,E,.\& Merkouris,A. Learning styles and critical thinking relationship in baccalaureate nursing education: A systematic review: Nurse Education Today. 2014; 34: 362-371. PMid:23830067 http://dx.doi.org/10.1016/j.nedt.2013.06.004

[30] Gongora-Ortega J; Segovia-Bernal Y; Valdivia-Martinez Jde J; Galaviz-DeAnda JM; Prado-Aguilar CA. Educational interventions to improve the effectiveness in clinical competence of general practitioners: problem-based versus critical reading-based learning. BMC Med Educ. 2012; 12: 53. Available from: http://reference.medscape.com/medline/abstract/22784406 PMid:22784406 http://dx.doi.org/10.1186/1472-6920-12-53

[31] Hood K., Leech M., Cant R., Gilbee A., Baulch J. Transforming nursing education: Development and evaluation of interprofessional clinical skills training for students on clinical placement. Journal of Nursing Education and Practice. 2014; 4(8). http://dx.doi.org/10.5430/jnep.v4n8p97 